\section{Summary and Conclusions}

A brief review is given of the various materials used in treatment that have been responsible in the past for conveying tetanus.

In the present investigation 666 samples of various forms of dressing materials were examined for tetanus bacilli by 14 public health laboratories situated in different parts of England.

Tetanus bacilli were isolated from 23 samples. Of these, all but three were of unbleached cotton-wool or cotton-wool bandages, most of them coming from a single firm.

These results suggest that contaminated dressings are a possible source of post-operative tetanus. Contaminated gloves may be of equal or greater danger, but no observations were made on them.

It is concluded that every attempt should be made to prevent tetanus spores being carried into the theatre by air, street dust, dressings, or in other ways.

All dressings should be sterilized before being taken into the theatre suite, and not in the theatre suite itself.

We thank all members of the regional hospital boards and hospital management committees who provided the necessary samples for examination.

\section{REFERENCES}

Armstrong, C. (1925). Publ. Hlth Rep. (Wash.), 40, 1351.

Bulloch, W., Lampitt, L. H., and Bushill, J. H. (1929). Spec. Rep. Ser. med. Res. Coun. (Lond.), No. 138.

Cane, L. H. (1938). Lancet, 2, 1059.

Carini, A. (1904). Zbl. Bakt., I. Abt. Orig., 37, 48.

Dalrymple-Champneys, W. (1936). Proc. roy. Soc. Med., 29, 465.

Durand, R. (1919). Abstr. Bact., 3, 292.

Fildes, P. (1925a). Brit. J. exp. Path., 6, 62.

- (1925b). Ibid., 6, 91.

Gilles, E. C. (1937). J. Amer. med. Ass., 109, 484

Goodhart, G. W., and McIntosh, J. (1941). J. Obstet. Gynaec. Brit. Emp., 48, 400.

Greenberg, L. (1949). Canad. med. Ass. J., 60, 4.

Hills, S. (1946). N.Z. med. J., 45, 419.

Johnson, D. W. (1956). Med. J. Aust., 2, 710.

Kerrin, J. C. (1929). Brit. J. exp. Path., 10, 370.

Lowbury, E. J. L., and Lilly, H. A. (1958). Brit. med. J., 2, 1334.

McCoy, G. W., Leake, J. P., and Corbitt, H. B. (1917). Publ. Hlth Rep. (Wash.), 32, 1450.

Mackie, T. J., McLachlan, D. G. S., and Anderson, E. J. M. (1929). Certain Factors that Promote the Development of the Tetanus Bacillus in the Tissues, With Special Reference to Post-operative Tetanus; An Experimental Inquiry. H.M.S.O., Edinburgh.

Murray, E. G. D., and Denton, G. D. (1949). Canad. med. Ass. J., $60,1$.

Nicolaier, A. (1884). Dtsch. med. Wschr., 10, 842.

Ostertag, H. (1942). Z. Hyg. Infekt.-Kr., 123, 698.

Porteous, E. R. (1934). Edinb. med. J., 41, 245.

Pulvertaft, R. J. V. (1937). Brit. med. J., 1, 441

Report (1907). J. trop. Med. Hyg., 10, 33.

— (1908). Brit. med. J., 1, 892.

- (1941). J. Obstet. Gynaec. Brit. Emp., 48, 394.

- (1958). Chief Medical Officer, Ministry of Health, for 1957.

Robinson, D. T., McLeod, J. W., and Downie, A. W. (1946). Lancet i, 152 .

Sevitt, S. (1949). Ibid., 2, 1075.

Smith, T. (1908). Trans. Chicago path. Soc., 7, 113 (No. 4, p. 1).

Sternberg, H. (1931). Zbl. Chirurg., 58, 2815.

Tremewan, H. C. (1946). N.Z. med. J., 45, 312.

Tuck, G. L. (1904). J. Path. Bact., 9, 38.

Tulloch, W. J. (1919). J. Hyg. (Camb.), 18, 103.

Welch, H., Slocum. G. G., and Herwick, R. P. (1942). J. Amer. med. Ass.. 120, 361.

Wright, H. D. (1930). Univ. Coli. Hosp. Mag. (Lond.), 15, 64.

Zweifel, P. (1910). Münch. med. Wschr., 57, 1787.

\section{RED-CELL APLASIA AND BENIGN THYMOMA}

STUDIES ON A CASE RESPONDING TO PREDNISONE

BY

E. H. O. PARRY, M.B., M.R.C.P.

G. S. KILPATRICK, M.D., M.R.C.P.Ed.

AND

\section{R. M. HARDISTY, M.D., M.R.C.P.} From the Royal Infirmary, Cardiff

In 1928 Matras and Priesel described aplastic anaemia associated with a thymic tumour. Since then reports of 16 similar cases have been published (see Soutter et al., 1957). The bone-marrow aplasia has usually been shown to affect the red-cell series only, although pancytopenia has also been described.

We report the case of a patient with pure red-cell aplasia and a benign thymic tumour in whom thymectomy had no effect on the anaemia. Subsequently, prednisone therapy was followed by the restoration of normal erythropoiesis. An attempt to demonstrate the presence of an inhibitor of erythropoiesis in the patient's plasma was unsuccessful.

\section{Case Report}

The patient was a widow aged 71 . At the age of 58 she had angina of effort, and, as she was said to be anaemic, was treated with an oral liver preparation for a few months. Subsequently she had slight effort dyspnoea, which increased after an attack of "influenza" in November, 1956. She was then treated with injections of liver for five months without benefit. At no stage were there any symptoms suggestive of myasthenia gravis, nor had she taken any marrow-depressant drugs.

She was admitted to Cardiff Royal Infirmary on July 17 , 1957, when she was found to have profound anaemia and senile purpura. Blood examination on admission gave the following results: Haemoglobin, 4.3 g. $/ 100 \mathrm{ml}$. (29\%); R.B.C., $1,300.000 /$ c.mm. ; P.C.V., $14 \%$; M.C.H.C., $31 \%$; M.C.V., 107 cubic microns ; reticulocytes, $0.2 \%(2,600 /$ c.mm.) ; W.B.C., 7.300/c.mm. (normal differential); platelets, $276,000 /$ c.mm. After an intravenous injection of Fe-59 the plasma half-clearance time was found to be 300 minutes (normal 70-120 minutes) and the iron utilization nil up to 18 days. The mean survival of normal red cells in the patient's circulation was 91 days. The direct anti-humanglobulin test was negative; serum iron, $260 \mu \mathrm{g} . / 100 \mathrm{ml}$.; and serum vitamin $B_{12}, 306 \mu \mu \mathrm{g} . / 100 \mathrm{ml}$. Serum proteins measured $6.1 \mathrm{~g} . / 100 \mathrm{ml}$. (albumin $3.6 \mathrm{~g}$., globulin $2.5 \mathrm{~g}$.) ; serum bilirubin, $0.4 \mathrm{mg} . / 100 \mathrm{ml}$.; alkaline phosphatase, 9.7 K-A units; thymol turbidity, 2 units; and blood urea, $24 \mathrm{mg} . / 100 \mathrm{ml}$. Wassermann reaction and Kahn test were negative. A histamine test meal showed free acid. Aminoacid chromatography of the urine was within normal limits. Iliac crest puncture revealed an almost complete absence of red-cell precursors; leucocyte and platelet formation appeared normal. A chest $x$-ray film showed a rounded opacity in the lower part of the right anterior mediastinum. The radiological appearances were suggestive of a thymoma.

For four months the patient was treated by repeated blood transfusions; the haemoglobin fell at a rate of approximately $1 \%$ a day between transfusions, as shown in the Chart, but leucocyte and platelet counts were normal throughout. Reticulocytes were never seen except shortly after transfusion. On November 13 the anterior mediastinal tumour was removed by Mr. D. M. E. Thomas; it was encapsulated, was $10 \mathrm{~cm}$. in diameter, and histological examination (Dr. R. M. E. Seal) showed that it was a benign thymoma. The marrow from a rib removed at 
operation was of less than average cellularity and contained practically no erythropoietic tissue.

The patient's post-operative course was uneventful, but her haemoglobin continued to fall at the pre-operative rate; no reticulocytes were seen on repeated examination and further blood transfusion was necessary.

Six weeks after operation, treatment with prednisone, $60 \mathrm{mg}$. daily, was started. During the next 15 days the reticulocyte count rose to $116.000 /$ c.mm. (see Chart). At this time the haemoglobin was $12.5 \mathrm{~g} . / 100 \mathrm{ml}$. (84\%) and it remained above $12 \mathrm{~g} . / 100 \mathrm{ml}$. for the rest of her life ;

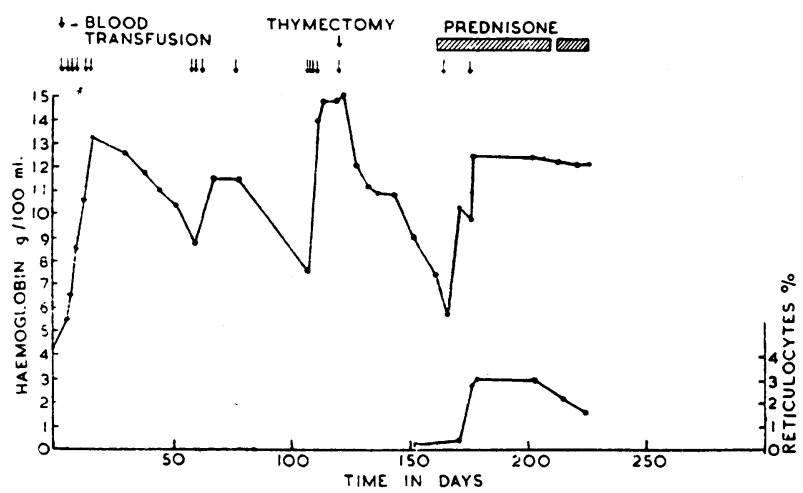

Haematological and therapeutic data in patient with red-cell aplasia and benign thymoma.

no further transfusions were needed. On the forty-second day of prednisone treatment the bone marrow showed active normoblastic erythropoiesis with a myeloid: erythroid ratio of 3:1. Prednisone was then gradually withdrawn without any significant fall in haemoglobin or reticulocyte count during the subsequent 20 days. Towards the end of this period the patient developed staphylococcal septicaemia and died, despite intensive chemotherapy.

Post-mortem examination revealed an abscess over the sacrum and multiple metastatic staphylococcal lesions. Red marrow filled the sternum and about three-quarters of the proximal part of the femur. Sections of ribs and femur showed normal haemopoietic marrow with numerous redcell precursors.

\section{Animal Experiments}

Because of the reported association between thymic tumours and red-cell aplasia an attempt was made to demonstrate a humoral factor in the plasma of our patient, capable of depressing red-cell production in experimental animals.

\section{Materials and Method}

The animals used were female Wistar rats weighing 200-350 g. They were anaesthetized and $2 \mathrm{ml}$. of heparinized plasma was injected intravenously by direct cannulation of one jugular vein. Twenty-four hours later the opposite jugular vein was cannulated and a further $2 \mathrm{ml}$. of plasma injected, followed by $1 \mathrm{ml}$. of a buffered sodium citrate solution containing approximately $1 \mu \mathrm{c}$ of radioactive iron (Fe-59). After a further 24 hours blood was obtained by cardiac puncture and the animal was destroyed. At the beginning and end of each experiment a specimen of blood was obtained from the tail, and the haemoglobin, P.C.V., and reticulocyte count were determined.

The radioactivity of the heparinized cardiac blood was determined by direct $\gamma$-counting in a well-type scintillation counter, and the percentage of injected iron utilized for haemoglobin synthesis was calculated in the following way:

$\%$ utilization $\mathrm{Fe}-59=$ activity in counts $/ \mathrm{sec} . / \mathrm{ml}$. blood $\times$ blood vol. $\times 100$ total activity injected in counts/sec.
Belcher et al. (1954), using " August" rats, found the blood volume to be equivalent to $5.3 \mathrm{ml} . / 100 \mathrm{~g}$. weight, and for the purposes of our calculations this figure was assumed to apply to our animals.

Three identical experiments were carried out as follows, using four animals on each occasion:

Experiment 1.-With patient's plasma, obtained before thymectomy and while no treatment other than blood transfusion was being given. All the animals survived.

Experiment 2.-With patient's plasma, post-operatively and after prednisone had been given. Two of the animals died.

Experiment 3.-With pooled normal human plasma. One animal died and one deteriorated so much that the second injection of plasma was not given.

Results

The iron-utilization figures, as a percentage of the injected dose of $\mathrm{Fe}-59$ for each experiment, are as follows :

\begin{tabular}{rr|c|c|c}
\hline & & Experiment 1 & Experiment 2 & Experiment 3 \\
\hline Rat 1 &.. & $31 \%$ & $40 \%$ & $39 \%$ \\
$\# 2$ & $\ldots$ & $42 \%$ & $42 \%$ & $29 \%$ \\
$\# 34$ & $\cdots$ & $38 \%$ & - & $=$
\end{tabular}

Although there were variations in the haemoglobin and reticulocyte counts during these experiments, the figures above show that the effect of the patient's plasma obtained before treatment on erythropoietic activity in the rats was not significantly different from that of normal plasma or from the patient's own plasma obtained after treatment. The percentage utilization of iron for haemoglobin synthesis in each case was of the same order as that found by Lamerton et al. (1956) in normal August rats.

The method of investigation employed in this study has its limitations, and we can only say that no humoral factor was demonstrated by the methods used. For example, erythropoiesis might have been inhibited had the plasma been given for a longer time.

\section{Discussion}

The association between thymic tumours and red-cell aplasia is sufficiently well established to suggest a causal relationship, but this has never been demonstrated experimentally. Loeb (1956) failed to reproduce anaemia when he injected $250 \mathrm{ml}$. of fresh plasma from a patient with a benign thymoma and red-cell aplasia into a normal adult recipient. Our patient's plasma produced no demonstrable effect on erythropoiesis when injected into normal rats in proportionately much greater amounts. These studies thus fail to provide experimental evidence of a humoral mechanism.

In our patient thymectomy had no demonstrable beneficial effect, whereas subsequent prednisone therapy was associated with a complete haematological remission which was maintained until the patient's death from other causes two months later.

Six of the 10 patients in whom the results of thymectomy have been reported (Soutter et al., 1957) have had a haematological remission at some stage after operation, but in only two (Humphreys and Southworth, 1945 ; Barquet Chediak et al., 1953) was this immediate, maintained, and unassociated with other therapy or operation. Chalmers and Boheimer (1954) reported the successful use of corticotrophin after thymectomy and splenectomy in two patients. Neither of the patients of Ross et al. (1954), however, improved despite 
the use of corticotrophin after thymectomy in one and splenectomy and thymectomy in the other. The pathogenesis of this condition remains obscure, but these various results of treatment are compatible with the concept that thymectomy may result in the removal of an inhibiting humural factor, so allowing normal erythropoiesis to take place either spontaneously or under the influence of steroids.

\section{Summary}

A case of benign thymoma and red-cell aplasia is described. Thymectomy did not produce a haematological remission, but normal erythropoiesis occurred later during treatment with prednisone. The patient's plasma did not inhibit erythropoiesis when injected into normal rats.

We are indebted to Dr. W. Phillips, under whose care this patient was admitted; to Dr. J. D. P. Graham for assistance with the animal experiments; to Mr. R. G. Wood for help with the isotope studies; and to Mr. D. M. E. Thomas and Dr. R. M. E. Seal, of Sully Hospital. Facilities for doing the experimental studies were made available to one of us (G. S. K.) during the tenure of a Research Fellowship in Medicine in the Royal Infirmary, Cardiff.

REFERENCES

Barquet Chediak, A., Fuste, R., and Vazquez Rosales, G. (1953). Arch. Hosp. univ. (Habana), 5, 27.

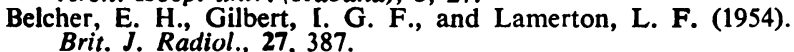

Chalmers, J. N. M., and Boheimer, K. (1954). Brit. med. J., 2, 1514 .

Humphreys, G. H. II, and Southworth, H. (1945). Amer. J. med. Sci.. 210, 501.

Lamerton, L. F., Belcher, E. H., and Harriss, E. B. (1956). Proc. roy. Soc. Med., 49, 863

Loeb, V , jun. (1956). J. Amer. med. Ass., 160, 1319.

Matras, A., and Priesel, A. (1928). Beitr. path. Anat., 80, 270.

Ross, J. F., Finch, S. C., Street, R. B., and Strieder, J. W. (1954). Blood, 9, 935 .

Soutter, L., Sommers, S., Relman, A. S., and Emerson, C. P. (1957). Ann. Surg., 146, 424.

\section{ROLE OF OSMOTIC DIURESIS IN IMPAIRMENT OF CONCENTRATING ABILITY IN RENAL DISEASE} BY

E. J. DORHOUT MEES, M.D.

From the Medical Department, University Hospital, Utrecht, The Netherlands

It has been suggested by Platt (1952) that the loss of " concentrating power" (osmotic ceiling), which is so constant a feature of chronic renal insufficiency, might be, at least partly, due to osmotic diuresis. He pointed out that in nephropathies there often is anatomical as well as functional evidence of increased activity per nephron. Osmotic diuresis may be constantly present in these conditions, not only as a result of elevated blood levels of solutes-for example, of urea-but also by an increased filtration rate per nephron.

Direct proof of this attractive hypothesis has not yet been given. Several authors (Nickel et al., 1953; White and Rubin, 1954 ; Bull, 1956) have reported a linear relationship between flow and load in their patients, which they regarded as an argument for the presence of osmotic diuresis. This, however, is not conclusive, because such relationships may also be observed under normal conditions - for example, during a concentration test (McCance, 1945) or during maximal water diuresis (Schoen, 1957).
To determine whether and to what extent osmotic diuresis is responsible for the loss of concentrating power in a particular patient, his flow-load relations must be compared with those of norinal people.

In normal man, during acute experiments and maximal antidiuretic hormone activity, osmotic diuresis is characterized by a certain relation between urine flow and concentration (Rapoport et al., 1949). In most cases this relation can be expressed by the formula:

$$
\frac{C_{u}}{C_{p}}=\frac{V+A}{V}
$$

Formula 1

where $C_{u}$ and $C_{p}$ represent total osmolar concentration in urine and plasma, $V$ the urine flow, and $A$ a quantity of water which if added to the urine would make it iso-osmolar with the plasma. This factor $A$ has been called "water economy" (West and Rapoport, 1950) or " negative free water clearance," and reaches a maximum which is designated as $\mathrm{T}^{c} \mathrm{H}_{2} \mathrm{O}$ by Smith and his school. When, at a certain flow, this maximum has been reached it can thus be calculated:

$$
\mathrm{T}^{\mathrm{c}} \mathrm{H}_{2} \mathrm{O}=\mathrm{V}\left(\frac{\mathrm{Cu}}{\mathrm{C}_{\mathrm{p}}}-1\right)
$$

Formula 2

In order to investigate the question to what extent osmotic diuresis is present under conditions of everyday life in renal patients, we have established the "flow-load relation" in these patients during maximal antidiuresis with and without additional osmotic loading and compared the results with those obtained in normal people under the same conditions.

\section{Materials and Methods}

All patients were submitted to a standard concentration test and to a mannitol infusion. These experiments were often done in succession. When we were afraid that severe fluid deprivation would not be well tolerated, thirsting was reduced to 12 hours and a pitressin-tannate-in-oil injection was given in addition, to provide for maximal antidiuresis. Mannitol was infused as a $15 \%$ solution in amounts varying from 75 to 150 g., during one to one and half hours. After the infusion was finished, urine was collected in portions of $100-200 \mathrm{ml}$. by spontaneous voiding, in at least four successive periods. Osmolarity was measured by freezing-point determination according to the Johlin (1931) principle. For calculation of the $\mathrm{T}^{c} \mathrm{H}_{2} \mathrm{O}$ we used the average "water economy" (formula 2) from all periods during which serum mannitol concentrations were at least $350 \mathrm{mg}$. per $100 \mathrm{ml}$.

The subjects were divided into four groups. Group 1 consisted of 10 normal persons. One of these subjects (No. 1 in the Table) was examined several times in different circumstances. The flow-load relation curve thus obtained was used as a standard with which the results obtained with the other individuals were compared.

-In group 2 the data were collected from nine patients with probably chronic nephritis, and in group 3 from five patients in whom predominant tubular damage could be expected-two with hypercalcaemia whose history is reported elsewhere (Dorhout Mees, 1957); two with tubular necrosis 32 and 28 days respectively after the beginning of anuria ; and one with unexplained renal diabetes insipidus. Group 4 is a miscellaneous group, including two patients with one kidney, one with renal vein thrombosis, and two others in whom renal impairment of undetermined origin was found accidentally. 